\title{
The influence of cereal and dairy consumption on the lrish diet: implications for developing food-based dietary guidelines
}

\author{
SJ Burke*, MJ Gibney, NA O'Dwyer and SN McCarthy \\ Department of Clinical Medicine, Trinity Centre for Health Sciences, St. James's Hospital, Dublin 8, Republic of Ireland
}

Submitted 21 July 2004: Accepted 9 November 2004

\begin{abstract}
Objectives: To estimate the intakes of cereal and dairy products and their contribution to nutrient intakes in men and women from the Republic of Ireland with a view to formulating food-based dietary guidelines.

Design: The North/South Ireland Food Consumption Survey established a database of habitual food and drink consumption using a 7-day food diary. From this database all cereal and dairy products from recipes and identifiable sources were identified and a new database was generated from which analysis of the role of cereal and dairy products in the diet was carried out.

Results: Almost $100 \%$ of the population consumed cereal and dairy products over the course of the survey week. In general, men consumed significantly more cereal and dairy products than did women $(P<0.05)$. Cereal products made an important contribution to the mean daily intakes of energy (26\%), protein (21\%), fat (13\%), carbohydrate (41\%), fibre (45\%), iron (43\%) and folate (27\%). Dairy products also contributed largely to the mean daily intakes of energy (11\%), protein (14\%), fat (17\%), calcium (48\%), phosphorus (24\%) and vitamin A (27\%). Analysis of nutrient intakes across tertiles of cereal and dairy consumption showed that high consumers of wholemeal bread, breakfast cereals, reduced-fat milk and yoghurt had lower fat and higher carbohydrate, fibre and micronutrient intakes than low consumers of these foods.

Conclusions: Findings from the present study could be used to develop effective health strategies to implement changes in cereal and dairy consumption that could alter fat, fibre and micronutrient intakes in the diet.
\end{abstract}

Keywords
Cereal products
Dairy products
Nutrients
Ireland
Food-based dietary guidelines
Food-based dietary guidelines (FBDG) are guidelines derived from nutrient targets or dietary goals that are translated into 'food-based guidelines' in order to be adopted by the general population ${ }^{1}$. FBDG need to consider the total diet, be based on prevailing patterns of food and nutrient intake, be culturally acceptable, and recognise the prevailing social and economic conditions that affect food availability. They should also be flexible and suit different subgroups of the population if necessary.

The advent of the North/South Ireland Food Consumption Survey (NSIFCS) will facilitate the development of culturally specific, evidence-based FBDG that will shape public health nutrition in Ireland in the medium term. Whereas it is perfectly appropriate to prepare summary data of the primary findings of an all-Ireland dietary survey outside the peer review system (www.iuna.net), detailed analysis of such databases to inform governmental and non-governmental organisations about preferred evidence-based public health nutrition strategies should be subject to the peer review system.
Figures from the Central Statistics Office ${ }^{2}$ show that increasing amounts of money are being spent on food in Ireland, and this holds true for cereal and dairy products. Preliminary analysis of the primary data of the NSIFCS shows that the food categories of cereal and dairy products together make important contributions to energy, macronutrient and micronutrient intakes in the Irish population ${ }^{3}$. Clearly these staples shape major elements of the Irish diet and merit a progressively more detailed analysis in the context of FBDG. Comparable studies in the $\mathrm{UK}^{4}$ and Italy ${ }^{5}$ reveal similar conclusions regarding their quantitative importance in the diet.

Published research from the NSIFCS has highlighted areas of public concern for the Irish population. This work has shown a need to reduce intake of dietary fat and increase intakes of carbohydrate ${ }^{6}$, fibre ${ }^{7}$, folate, riboflavin, and vitamins $\mathrm{A}$ and $\mathrm{D}^{8}$, along with intakes of certain minerals such as iron, calcium, copper and zinc (this is especially true for women $)^{9}$, in the Irish population. The information presented in this paper on the role of cereal and dairy products in the Irish diet may potentially be used 
to formulate FBDG in order to try and combat some of these public health nutrition problems.

The present study represents one of several such analyses of the NSIFCS database, which are scheduled to include analyses covering breakfast cereals ${ }^{10}$, meats ${ }^{11}$, fruits and vegetables ${ }^{12}$ and meals outside the home ${ }^{13}$ in addition to the present study of cereal- and dairy-based foods. This study sets out to provide a basic but systematic analysis of the role of cereal and dairy products in the Irish diet. It also aims to examine the quality of the diet in those who are high, medium and low consumers of cereal and dairy products, as well as examining the potential uses of this information for FBDG.

\section{Methods}

The NSIFCS was a cross-sectional study of food and nutrient intakes in a random representative sample of adults aged 18-64 years from Northern Ireland and the Republic of Ireland. A more detailed account of the sampling procedures and methodologies is provided elsewhere ${ }^{14,15}$. In brief, a 7-day food diary was used to measure food intakes. Subjects recorded the amount of each item of food and drink consumed and details of recipes used were requested. The food diaries were analysed using $\mathrm{WISP}^{\circledR}$ (Weighed Intake Software Program; Tinuviel Software, Warrington, UK). WISP ${ }^{\circledR}$ uses McCance and Widdowson's food tables and published supplements to generate nutrient data ${ }^{16-25}$. New food codes were generated for new products on the market and for recipes. Subsequently, a recipe database was generated so that analysis of recipes could be carried out. Additional information on health and lifestyle, physical activity and attitudes to food and health was collected using selfadministered questionnaires. Anthropometric measurements were also taken ${ }^{26}$. For this analysis, only data obtained for the Republic of Ireland were used ( $n=958$ ).

The main nutrient database comprised approximately 160000 rows of data that described every food and drink item consumed by each respondent for every meal for each of the seven recording days. For each item consumed, the day, time of consumption, meal number in the day, meal definition, weight of food/drink and a full nutrient breakdown for the amount consumed were recorded in the database. Each cereal and dairy product consumed by the respondents of the survey was identified. All cereal and dairy products from identifiable sources (e.g. when the respondent recorded eating rice) and from recipes (e.g. the cheese in an omelette) were used to form a new cereal and dairy database. Each food in the new database was categorised to form one of 16 food groups including total cereals and total dairy. A detailed description of the cereal and dairy food groups formed and the foods in each group can be found in the Appendix. Because of the large percentage consumers of milk, it was possible to create full-fat and reduced-fat milk groups. However, this was not feasible for the other dairy food groups because of the low percentage consumers of low-fat varieties in each dairy food group.

Data analysis was carried out using SPSS ${ }^{\circledR}$ version 10.0 (SPSS Inc., Chicago, IL, USA). Mean \pm standard deviation (SD) was calculated for mean daily intakes of cereal and dairy products, mean daily intakes of nutrients from cereal and dairy products (absolute amounts and nutrients per $10 \mathrm{MJ}$ of energy) and the percentage contribution of cereal and dairy products to the mean daily intakes of nutrients. Analysis was done according to gender, age group (18-35 years, 36-50 years, 51-64 years), location, marital status, body mass index (BMI) and social class. Only variables that showed significant differences in previous analysis for this database were included here. The mean daily intakes of cereal and dairy products $\left(\mathrm{g} \mathrm{day}^{-1}\right)$ were categorised into tertiles (for consumers only), and mean \pm SD values of percentage energy from macronutrients and of micronutrient and fibre intakes (per $10 \mathrm{MJ}$ of energy) were calculated for low, medium and high consumers of cereal and dairy products.

Statistical differences between groups were assessed using parametric tests if the data were normally distributed. If the data were not normally distributed, they were transformed using the square-root or the natural-log $(\ln )$ transformation. If the transformed data produced a normal distribution, parametric tests were performed on the transformed data. However, if the transformed data did not give a normal distribution, nonparametric tests were carried out on the original data. For data that were normally distributed, independent $t$-tests were used to assess differences between gender and between location and marital status within each sex. Oneway analysis of variance was used to determine whether significant differences in mean values existed between age groups, BMI categories and social class within each sex. Where significant differences existed, homogeneity of variance was tested using Levene's test. Comparisons were made using the Scheffe post hoc comparisons test to identify which means differed when the values satisfied Levene's test. For values that did not comply with Levene's test, the Tamhane post hoc multiple comparisons test was used to identify the means that differed. For data that were not normally distributed, the Mann-Whitney test was used to determine significant differences between means. Values of $P<0.05$ were taken as significantly different.

\section{Results}

Data on the intakes of cereal and dairy products, their contribution to macronutrient intakes, and fibre and micronutrient intakes from cereal and dairy products are presented in Tables 1-3 for consumers of the food group. In general, men consumed significantly more cereal and dairy products than women. Men consumed significantly more white bread than women $(P<0.01)$, and women 


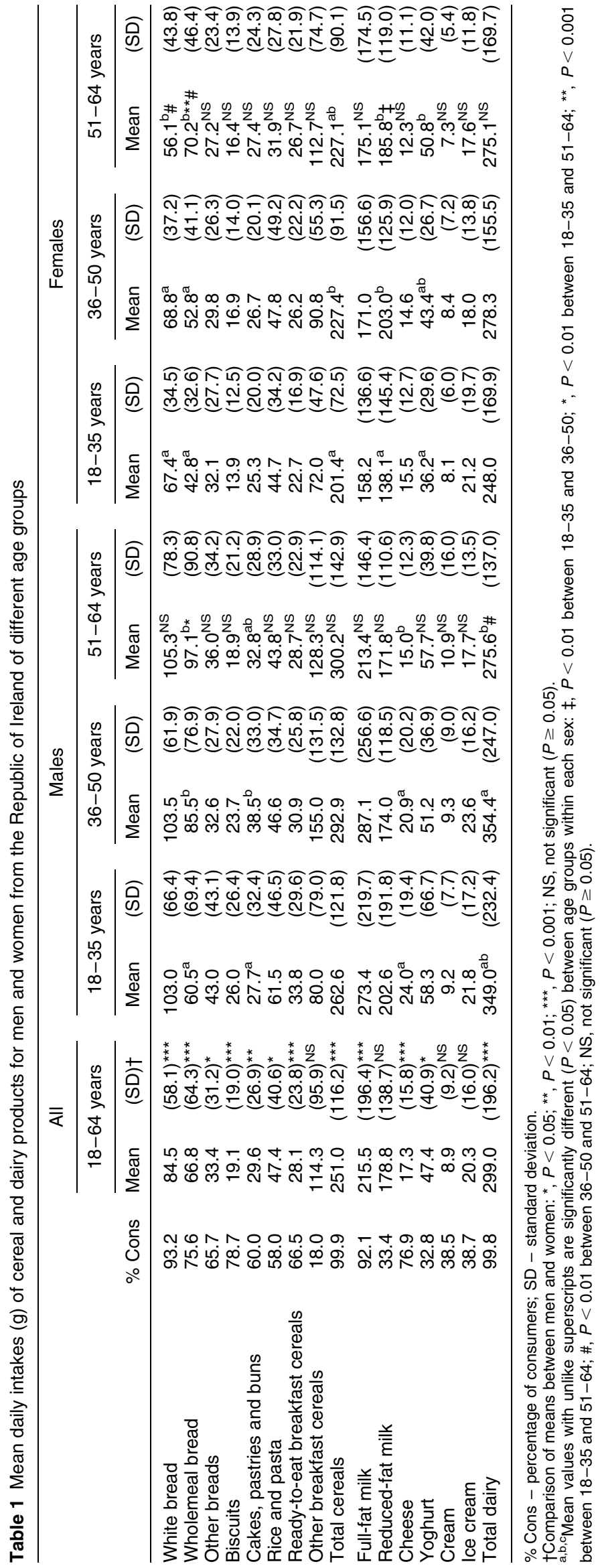


Intakes of cereal and dairy products in Ireland

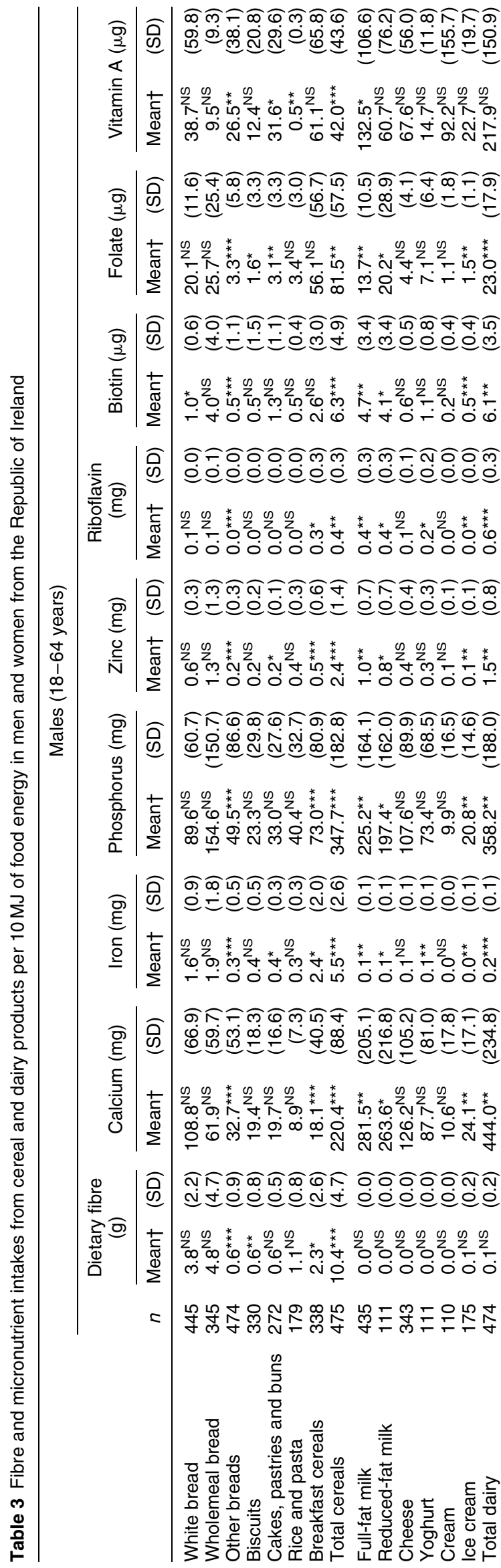

231

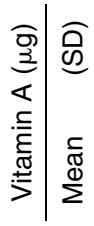

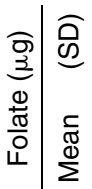

कิ

言

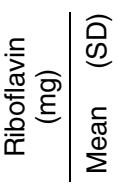

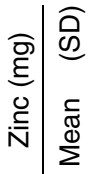

હે

$\stackrel{0}{\circ}$

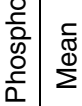

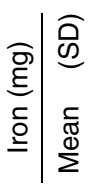

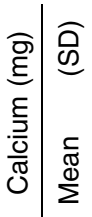

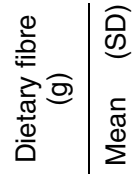

$=$

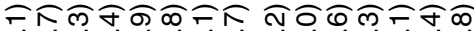

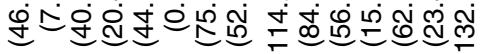

ம

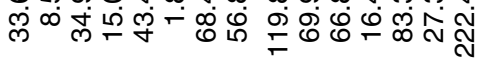

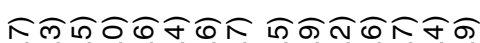

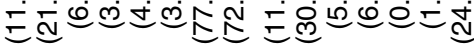

NT

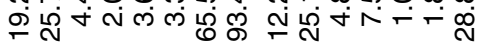

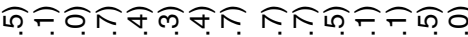

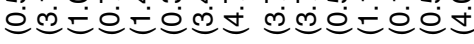

d)

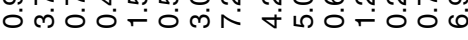

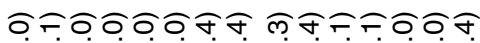

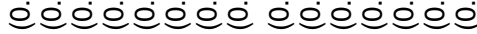

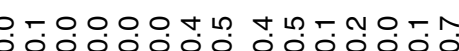

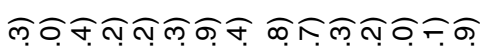

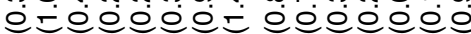


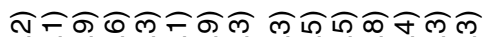

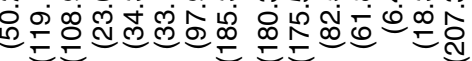

จ

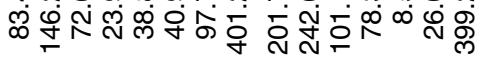

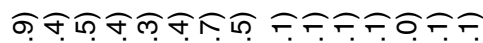

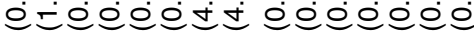

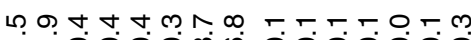

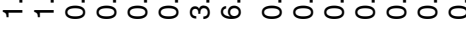

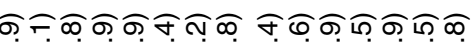

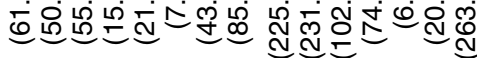

$0 m \wedge-0$ -

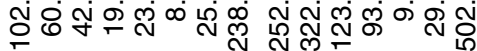

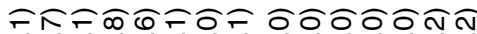

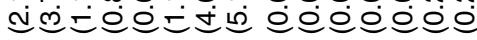

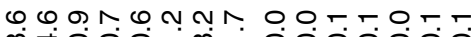
लम०००ण लः

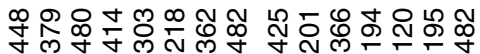

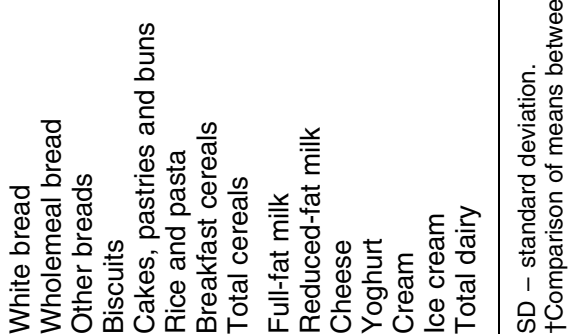


aged 18-35 years consumed significantly more white bread than women aged $51-64$ years $(P<0.01)$. White bread made the greatest contribution of cereals to energy and macronutrients. Consumption of wholemeal bread increased with increasing age in both men and women. Wholemeal bread made a significantly lower contribution to the mean daily intakes of macronutrients for 18-35year-old men than for 36-64-year-old men $(P<0.05)$, while it made a significantly higher contribution to macronutrient intakes in women aged 51-64 years than in all younger age groups $(P<0.01)$. However, older men and women (51-64 years) had significantly higher fibre and micronutrient intakes from wholemeal bread than younger men and women $(P<0.01)$. The greatest cereal contributors to the mean daily intake of fat were cakes, pastries \& buns at $6 \%$ and biscuits at $4 \%$. The percentage contribution of breakfast cereals to energy and macronutrients, and fibre and micronutrient intakes from breakfast cereals per $10 \mathrm{MJ}$, increased with increasing age in men and women, but these differences were not always significant.

Full-fat milk was the highest dairy contributor to mean daily energy, macronutrient and micronutrient intakes. Younger men (18-35 years) consumed more reduced-fat milk than older men, whereas younger women consumed significantly less reduced-fat milk than older age groups $(P<0.05)$. Women aged $18-35$ years also had a significantly lower percentage contribution to mean daily intake of all macronutrients, and lower micronutrient intakes per $10 \mathrm{MJ}$ from reduced-fat milk than older women $(P<0.05)$. Men aged $51-64$ years consumed significantly less cheese than men aged $18-35$ years $(P<0.001)$ and, in general, cheese contributed less to the intakes of macroand micronutrients in older men $(P<0.05)$. The intakes of cereal and dairy products and their contribution to nutrient intakes were also analysed by sociodemographic variables, but no particular patterns were observed across different sociodemographic groups.

The intakes of a wide range of nutrients were analysed for low, medium and high consumers of selected cereal products, but are presented here only for protein, fat and carbohydrate (as a percentage of food energy) and dietary fibre, calcium, iron and folate per $10 \mathrm{MJ}$ of energy (Table 4). In general, high consumers of cereal products (>317g for men, $>244 \mathrm{~g}$ for women) had higher intakes of energy, carbohydrate and dietary fibre than did low consumers, while their intakes of protein and fat were lower. The intake of calcium increased with increasing consumption of cereals; however, intakes of zinc, thiamin, folate and vitamin $\mathrm{B}_{12}$ were highest in low consumers of cereal products. Although some of the differences were statistically significant, the actual difference between the highest and lowest tertile was not of nutritional significance (e.g. $11.1 \mathrm{mg}$ vs. $10.3 \mathrm{mg}$ of zinc for women). Because of the small differences, it is difficult to identify food patterns to explain this. Higher intakes of white ( $>118 \mathrm{~g}$ for men, $>80 \mathrm{~g}$ for women) and wholemeal ( $>93 \mathrm{~g}$ for men, $>66 \mathrm{~g}$ for women) bread were associated with higher energy intakes. High consumers of wholemeal bread had significantly lower fat intakes than low consumers ( $P<0.05$ for men, $P<0.01$ for women). Intakes of dietary fibre were significantly lower in high consumers of white bread, but significantly higher in high consumers of wholemeal bread $(P<0.05)$. Intakes of micronutrients tended to decrease with increasing consumption of white bread, while increasing with greater consumption of wholemeal bread. In general, energy and fat intakes were higher while protein and micronutrient intakes were lower $(P<0.01)$ in high consumers of other breads ( $>42 \mathrm{~g}$ for men $>36 \mathrm{~g}$ for women), biscuits ( $>25 \mathrm{~g}$ for men, $>18 \mathrm{~g}$ for women) and cakes, pastries \& buns ( $>34 \mathrm{~g}$ for men, $>29 \mathrm{~g}$ for women), compared with low consumers. Intakes of fat $(P<0.01$ for men, $P<0.001$ for women) were lower while intakes of carbohydrate, dietary fibre $(P<0.01)$ and micronutrients were higher in high consumers of breakfast cereals ( $>55 \mathrm{~g}$ for men, $>45 \mathrm{~g}$ for women) compared with low consumers.

The intakes of a wide range of nutrients were analysed for low, medium and high consumers of selected dairy products, but are presented here only for protein, fat and carbohydrate (as a percentage of food energy) and dietary fibre, calcium, iron and folate per $10 \mathrm{MJ}$ of energy (Table 5 ). High consumers of dairy products $(>380 \mathrm{~g}$ for men, $>310 \mathrm{~g}$ for women) had significantly higher energy $(P<0.05)$, calcium and riboflavin $(P<0.001)$ intakes than low consumers. Intakes of protein $(P<0.001$ for men) and dietary fibre $(P<0.05)$ decreased with increasing dairy consumption. Food patterns were assessed, but could not identify any reasons for this. Intakes of other micronutrients were not consistent across tertiles. High consumers of full-fat milk ( $>317 \mathrm{~g}$ for men, $>195 \mathrm{~g}$ for women) had significantly higher intakes of energy $(P<0.001)$, fat $(P<0.01)$, calcium $(P<0.001)$ and riboflavin $(P<0.001$ for men) than low consumers, while intakes of protein, fibre $(P<0.001)$ and other micronutrients decreased with increasing consumption $(P<0.001)$. For women, intakes of fat were significantly lower $(P<0.01)$ while intakes of most micronutrients were significantly higher in high consumers of reduced-fat milk ( $>212 \mathrm{~g}$ ). High consumers of cheese ( $>23 \mathrm{~g}$ for men, $>15 \mathrm{~g}$ for women) had significantly higher energy $(P<0.001)$, fat $(P<0.01)$, calcium $(P<0.001)$ and vitamin A $(P<0.01$ for women) intakes and lower iron, potassium, thiamin and biotin $(P<0.05$ for men) intakes than low consumers of cheese. High yoghurt consumers ( $>64 \mathrm{~g}$ for men, $>53 \mathrm{~g}$ for women) had significantly lower fat intakes $(P<0.01)$ and higher intakes of nearly all micronutrients analysed than low consumers of yoghurt (differences were not always significant). In general, energy and fat intakes were higher in high cream consumers $(>9 \mathrm{~g}$ for men and women) $(P<0.05)$ than in low cream consumers. Nutrient intakes across tertiles 


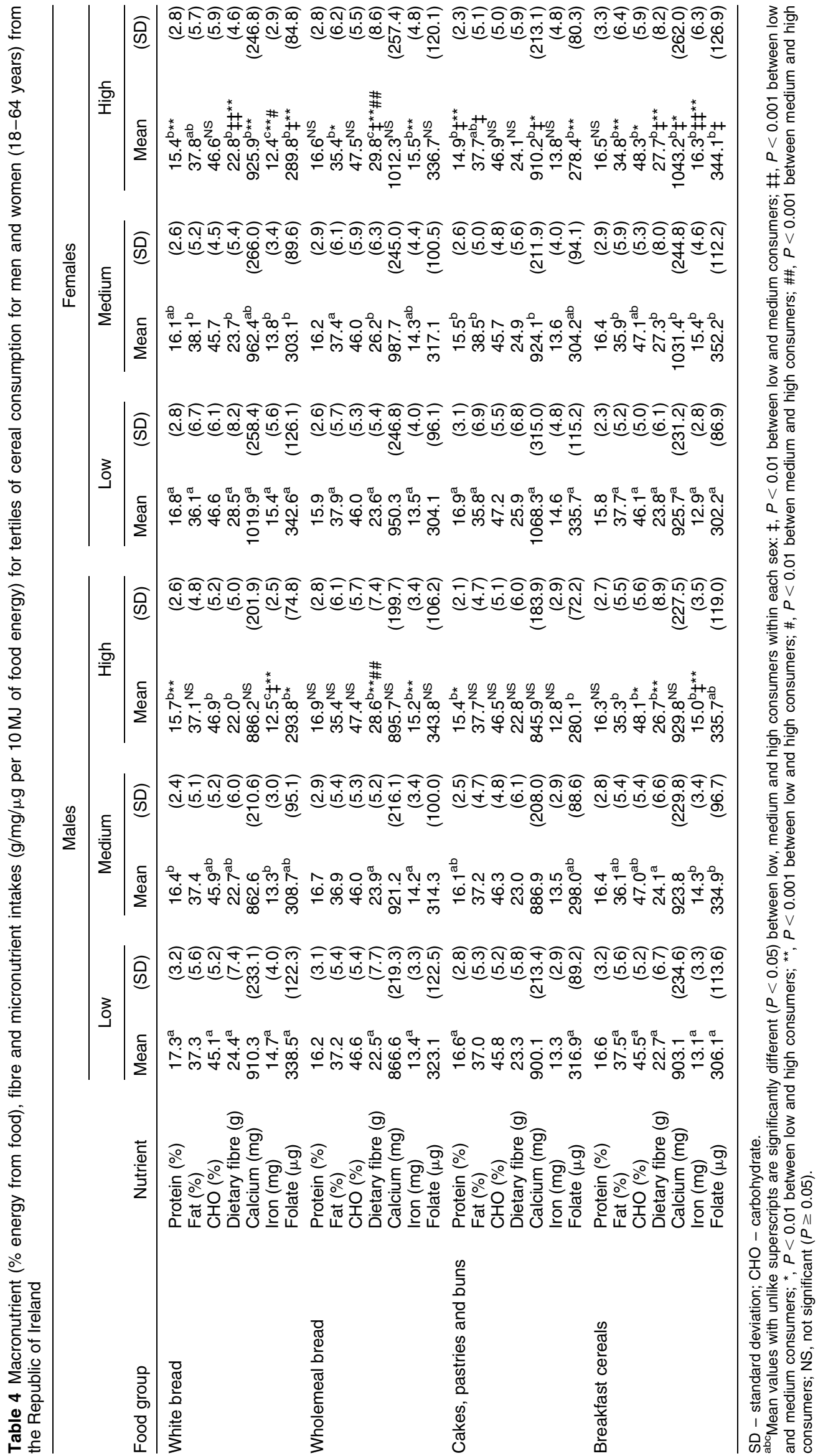


were not significantly different for men. However, females who were high consumers of cream had significantly lower intakes of potassium, thiamin and riboflavin $(P<0.05)$, phosphorus $(P<0.01)$ and calcium $(P<0.001)$ than low consumers. Differences across tertiles of ice cream consumption were not significant for men for intakes of any nutrient analysed. Among women, high consumers $(>22 \mathrm{~g})$ of ice cream had significantly higher energy and lower protein, dietary fibre and zinc intakes than low consumers $(P<0.05)$.

\section{Discussion}

The current analysis of the NSIFCS takes the form of multiple peer-reviewed papers which, both on an individual level and collectively, will help form national strategies for public health nutrition and education. The present study is one of this series of research papers, with the others covering breakfast cereals ${ }^{10}$, meat and meat products $^{11}$, fruits and vegetables ${ }^{12}$ and the food services sector $^{13}$. Taken together, cereal and dairy products account for more than one-third of all energy consumed, which represents a significant element of nutrient intake and is thus deserving of detailed analysis.

The majority of published papers in this field examine food intakes, nutrient intakes or the contribution of foods to nutrient intakes for the diet as a whole. Given that the focus of this paper is on only two food staples, the level of detail in the present paper is much greater than that of other studies. This paper therefore has the advantage of being able to present information on the intakes of cereal and dairy products, the contribution of these food groups to nutrient intakes, and nutrient intakes across tertiles of cereal and dairy consumption in one publication.

Comparisons between this and other peer-reviewed papers based on national dietary surveys are of limited value for a number of reasons. As with all published papers, differences in data collection methods make comparisons difficult. A 7-day record was used in this study whereas other regional or national nutrition surveys have used other data collection methods. For example, the Austrian $^{27}$ and Spanish ${ }^{28}$ surveys used a 24-hour recall, the Australian study ${ }^{29}$ used a food-frequency questionnaire, and the previous Irish study ${ }^{30}$ and a study carried out in East Germany ${ }^{31}$ used diet histories. Nutrition surveys are carried out on populations of different age groups, which again makes comparisons with the present adult population (18-64 years) difficult. For example, the Italian nutrition survey was carried out on individuals from the age of 1 year ${ }^{5}$ whereas the national dietary survey in Belgium was carried out on adults aged 25-74 years ${ }^{32}$. Another factor to be taken into account is that results can be presented as means, medians, frequency, total or serving size, which again makes comparisons between studies very difficult ${ }^{4,5,33-36}$. Survey duration is also a major source of variability in food consumption surveys when data are presented for consumers only ${ }^{37}$, and should be taken into account when making comparisons with other studies. Comparisons of recent nutrition studies (e.g. NSIFCS) with older, more dated studies (e.g. VERA (Verbundstudie Ernährungserhebung und Risikofaktorenanalytik) in West Germany in $1987 / 8^{38}$ ) can be misleading, as dietary patterns may have changed within the country since the survey was carried out and should be noted when comparing different studies.

One of the major methodological differences between studies is that the classification of foods is different in every study, again making comparisons between studies arduous. For example, in the present study, dairy products included full-fat milk, reduced-fat milk, cheese, yoghurt, cream and ice cream. In the NDNS (National Diet and Nutrition Survey) in Britain, dairy products contained whole milk, semi-skimmed milk, skimmed milk, other milk, cream, cottage cheese, other cheese, fromage frais, yoghurt, ice cream and other dairy desserts ${ }^{4}$, whereas in a comparable study in Italy, dairy products included milk, yoghurt, cream and cheese ${ }^{5}$. Great difficulties arise therefore when comparing, for example, the intake of lower-fat milk in Ireland with intakes in Britain and Italy. A common food classification system is needed to make data between studies comparable. This could be achieved with the use of a food coding system such as Eurocode 2 in all nutrition surveys ${ }^{39}$.

Another of the main methodological differences between this study and other published work is that results for consumers only are presented here, while the vast majority of other studies present the main results for the total population ${ }^{5,3436}$. Intakes of a given food for the total population can contain a significant number of zero values that will lower the overall mean intake. For example, in Ireland, the intake of reduced-fat milk for the total population was $60 \mathrm{~g}$ but only $33 \%$ of the population consumed it. When the intake for consumers only was examined, the mean intake increased three-fold to $179 \mathrm{~g}$. This illustrates the importance of having information for consumers of the food groups. This is particularly important for the development of FBDG, as strategies for increasing food intake can focus on (1) increasing the number of consumers, (2) increasing the frequency of intake among consumers or (3) increasing serving size among consumers ${ }^{40}$.

Allowing for difficulties in making comparisons with other studies as mentioned above, some broad comparisons can be made. Intakes of cereal and dairy products in Ireland appear to have decreased since 1990. The INNS (Irish National Nutrition Survey) ${ }^{30}$ reported higher intakes of nearly all cereal and dairy products than are reported here; however, different methodologies were used for food intake measurements in both studies. In general, quantities of cereal and dairy products consumed in Ireland were very similar to those consumed in Britain ${ }^{4}$. Notable differences were observed for the consumption of 
bread, in particular wholemeal bread where Irish people consumed 4-6 slices more per week. Men and women in Ireland also consumed 300-800 ml more full-fat milk per week than their British counterparts. British women appear to consume slightly more cheese and yoghurt than Irish women, but the maximum difference would be the equivalent of one portion per week. Comparisons of the percentage contribution of cereal and dairy products to macronutrient intake showed very little difference between the British study and the present study ${ }^{41}$. The present study also found that high consumers of wholemeal bread and breakfast cereals had lower fat and higher fibre and micronutrient intakes than did low consumers. High consumption of reduced-fat milk and yoghurt was also associated with lower fat and higher fibre and micronutrient intakes, particularly in women. However, a study in Spain found very little differences in nutrient intakes between low and high yoghurt consumers ${ }^{42}$.

Previous analysis of the NSIFCS database has highlighted areas of public health concern for the Irish population. Fat intakes were above the recommendation, while carbohydrate and fibre intakes were below the recommended level in Irish men and women ${ }^{6,7}$. Also, a substantial proportion of the population had folate, iron and calcium intakes which were below the average requirement ${ }^{8,9}$. Results from this paper may potentially be used to help alleviate some of these concerns through the development FBDG. For example, recommendations calling for increased consumption of wholemeal bread could help reduce the percentage energy from fat (by increasing the percentage energy from carbohydrate), increase fibre, folate and iron intakes, and would appear to result in a diet with better nutrient quality. This analysis also shows that $76 \%$ of the population consumed wholemeal bread and their mean daily intake of wholemeal bread was $66.8 \mathrm{~g}$ (almost two servings). Thus the number of consumers of wholemeal bread could be increased slightly, or the number of servings or serving size could be increased to increase wholemeal bread consumption. The substitution of wholemeal bread for white bread could also be encouraged in an attempt to increase wholemeal bread consumption.

In conclusion, examination of the contribution of individual staple foods to the diet provides very detailed analysis that can be used for the development of health strategies. Future analysis on food and nutrient intakes should be carried out for consumers of the food groups only, as consumer-only information is essential for the development of effective FBDG.

\section{Acknowledgements}

This project was funded by the Irish Government under the National Development Plan 2000-2006.

\section{References}

1 Eurodiet Working Party 2. A framework for food-based dietary guidelines in the European Union. Public Health Nutrition 2001; 4(2A): 293-305.

2 Central Statistics Office. Household Budget Survey 1999/2000. Dublin: Central Statistics Office, 2001.

3 Irish Universities Nutrition Alliance. North/South Ireland Food Consumption Survey. Summary Report. Dublin: Food Safety Promotion Board, 2001.

4 Henderson L, Gregory J, Swan G. The National Diet and Nutrition Survey: Adults aged 19-64 years. Vol. 1. London: HMSO, 2002.

5 Turrini A, Saba A, Perrone D, Cialfa E, D’Amicis A. Food consumption patterns in Italy: the INN-CA Study 1994-1996. European Journal of Clinical Nutrition 2001; 55: 571-88.

6 Harrington KE, McGowan MJ, Kiely M, Robson PJ, Livingstone MBE, Morrissey PA, et al. Macronutrient intakes and food sources in Irish adults: findings of the North/South Ireland Food Consumption Survey. Public Health Nutrition 2001; 4(5A): 1051-60.

7 Galvin MA, Kiely M, Harrington KE, Robson PJ, Moore R, Flynn A. The North/South Ireland Food Consumption Survey: the dietary fibre intake of Irish adults. Public Health Nutrition 2001; 4(5A): 1061-8.

8 O'Brien MM, Kiely M, Harrington KE, Robson PJ, Strain JJ, Flynn A. The North/South Ireland Food Consumption Survey: vitamin intakes in 18-64-year-old adults. Public Health Nutrition 2001; 4(5A): 1069-79.

9 Hannon EM, Kiely M, Harrington KE, Robson PJ, Strain JJ, Flynn A. The North/South Ireland Food Consumption Survey: mineral intakes in 18-64-year-old adults. Public Health Nutrition 2001; 4(5A): 1081-8.

10 Galvin MA, Kiely M, Flynn A. Impact of ready-to-eat breakfast cereal (RTEBC) consumption on adequacy of micronutrient intakes and compliance with dietary recommendations in Irish adults. Public Health Nutrition 2003; 6(4): 351-63.

11 Cosgrove M, Flynn A, Kiely M. Impact of disaggregation of composite foods on estimates of intakes of meat and meat products in Irish adult. Public Health Nutrition 2005; 8(3): 331-41.

12 O'Brien MM, Kiely M, Galvin MA, Flynn A. The importance of composite foods for estimates of vegetable and fruit intakes. Public Health Nutrition 2003; 6(7): 711-26.

13 O'Dwyer NA, Gibney MJ, Burke SJ, McCarthy SN. The influence of eating location on nutrient intakes in Irish adults: implications for developing food-based dietary guidelines. Public Health Nutrition 2005; 8(3): 262-9.

14 Kiely M, Flynn A, Harrington KE, Robson PJ, Cran G. Sampling description and procedures used to conduct the North/South Ireland Food Consumption Survey. Public Health Nutrition 2001; 4(5A): 1029-35.

15 Harrington KE, Robson PJ, Kiely M, Livingstone MBE, Lambe J, Gibney MJ. The North/South Ireland Food Consumption Survey: survey design and methodology. Public Health Nutrition 2001; 4(5A): 1037-42.

16 Holland B, Welch AA, Unwin ID, Buss DH, Paul AA, Southgate DAT. McCance \& Widdowson's The Composition of Foods, 5th ed. London: HMSO, 1995.

17 Holland B, Unwin ID, Buss DH. Cereal and Cereal Products. Third Supplement to McCance \& Widdowson's The Composition of Foods, 4th ed. London: HMSO, 1988.

18 Holland B, Unwin ID, Buss DH. Milk Products and Eggs. Fourth Supplement to McCance \& Widdowson's The Composition of Foods, 4th ed. London: HMSO, 1989.

19 Holland B, Unwin ID, Buss DH. Vegetables, Herbs and Spices. Fifth Supplement to McCance \& Widdowson's The Composition of Foods, 4 ed. London: HMSO, 1991.

20 Holland B, Unwin ID, Buss DH. Fruits and Nuts. First 
Supplement to McCance \& Widdowson's The Composition of Foods, 5th ed. London: HMSO, 1992.

21 Holland B, Welch AA, Buss DH. Vegetable Dishes. Second Supplement to McCance \& Widdowson's The Composition of Foods, 5th ed. London: HMSO, 1992.

22 Holland B, Brown J, Buss DH. Fish and Fish Products. Third Supplement to McCance \& Widdowson's The Composition of Foods, 5th ed. London: HMSO, 1993.

23 Chan W, Brown J, Buss DH. Miscellaneous Foods. Fourth Supplement to McCance \& Widdowson's The Composition of Foods, 5th ed. London: HMSO, 1994.

24 Chan W, Brown J, Lee SJ, Buss DH. Meat, Poultry and Game. Fifth Supplement to McCance \& Widdowson's The Composition of Foods, 5th ed. London: HMSO, 1995.

25 Chan W, Brown J, Church SM, Buss DH. Meat Products and Dishes. Sixth Supplement to McCance \& Widdowson's The Composition of Foods, 5th ed. London: HMSO, 1996.

26 McCarthy SN, Harrington KE, Kiely M, Flynn A, Robson PJ, Livingstone MBE, et al. Analyses of the anthropometric data from the North/South Ireland Food Consumption Survey. Public Health Nutrition 2001; 4(5A): 1099-106.

27 Elmadfa I, Burger P, Derndorfer E, Kiefer I, Kunze M, Konig J, et al. Osterreichisher Ernahrungsbericht 1998. Wien: Bundesministerium fur Gesundheit, Arbeit und Soziales/Bundesministerium fur Frauenangelegenheiten und Verbraucherschutz (Hrsg), 1999.

28 Serra-Majem L, Ribas L, Garcia-Closas R, Ramon JM, Salvador G, Farran A, et al. Llibre Blanc: Avaluacio de l'Estat Nutricional de la Poblacio Catalana (1992-93). Barcelona: Departament de Sanitat i Seguretat Social, 1996.

29 Australian Bureau of Statistics. National Health Survey: Users' Guide. Catalogue No. 4363.0. Canberra: Australian Bureau of Statistics, 1995.

30 Lee P, Cunningham K. Irish National Nutrition Survey. Dublin: Irish Nutrition and Dietetic Institute, 1990.

31 Hermann-Kunz E, Thamm M. Dietary recommendations and prevailing food and nutrient intakes in Germany. British Journal of Nutrition 1999; 81: S61-9.

32 De Backer G. Regional differences in dietary habits, coronary risk factors and mortality rates in Belgium. Design and methodology. Acta Cardiologica 1984; 39: 285-92.
33 Anttolainen M, Javanainen J, Kaartinen P, Lahti-Koski M, Lauronen J, Mannisto S, et al. The 1997 Dietary Survey of Finnish Adults. Helsinki: National Public Health Institute, 1998.

34 Pryer JA, Nichols R, Elliott P, Thakrar B, Brunner E, Marmot M. Dietary patterns among a national random sample of British adults. Journal of Epidemiology and Community Health 2001; 55: 29-37.

35 Fraser GE, Sabate J, Beeson WL, Strahan TM. A possible protective effect of nut consumption on risk of coronary heart disease. The Adventist Health Study. Archives of Internal Medicine 1992; 152: 1416-24.

36 Aranceta J, Perez Rodrigo C, Eguileor I, Marzana I, Gonzalez de Galdeano L, Saenz de Buruaga J. Food consumption patterns in the adult population of the Basque Country (EINUT-I). Public Health Nutrition 1998; 1(3): 185-92.

37 Lambe J, Kearney J, Leclercq C, Zunft HF, De Henauw S, Lamberg-Allardt CJ, et al. The influence of survey duration on estimates of food intakes and its relevance for public health nutrition and food safety issues. European Journal of Clinical Nutrition 2000; 54: 166-73.

38 Heseker H, Adolf T, Erberhardt W, Hartmann S, Herwig A, Kubler W, et al. Lebensmittel und Nahrstoffaufnahme Erwachsener in der Bundesrepublik Deutschland. VERASchriftenreihe. Niederkleen: Wissenschaftlicher Fachverlag Dr Fleck, 1992.

39 Ireland J, Erp-Baart AM, Charrondiere UR, Moller A, Smithers $G$, Trichopoulou A. Selection of a food classification system and a food composition database for future food consumption surveys. European Journal of Clinical Nutrition 2002; 56: $\mathrm{S} 33-\mathrm{S} 45$.

40 Gibney MJ. Development of food-based dietary guidelines: a case-study of fibre intake in Irish women. British Journal of Nutrition 1999; 81: S151-2.

41 Henderson L, Gregory J, Irving K, Swan G. The National Diet and Nutrition Survey: Adults aged 19-64 years. Vol. 2. London: HMSO, 2002.

42 Capdevila F, Marti-Henneberg C, Closa R, Escribano Subias J, Fernandez-Ballart J. Yoghurt in the Spanish diet: nutritional implications and socio-cultural aspects of its consumption. Public Health Nutrition 2003; 6(4): 333-40.

\section{Appendix - Components of cereal and dairy food groups}

\begin{tabular}{ll}
\hline Cereal and dairy food group & \multicolumn{1}{c}{ Components of cereal and dairy food group } \\
\hline White bread & White sliced and unsliced bread, white soda bread and white rolls \\
Wholemeal bread & $\begin{array}{l}\text { Wholemeal and brown sliced and unsliced bread, home-made brown bread } \\
\text { and wholemeal and brown rolls }\end{array}$ \\
Other breads & Scones, croissants, pizza, savoury breads, bread from recipes, etc. \\
Biscuits & Sweet biscuits, savoury biscuits and biscuits from recipes \\
Cakes, pastries and buns & Cakes, pastries and buns \\
Rice and pasta & Rice, cous-cous, pasta, noodles from identifiable sources and from recipes* \\
Ready-to-eat breakfast cerealst & Ready-to-eat breakfast cereals \\
Other breakfast cereals† & Other breakfast cereals, e.g. porridge and Ready Brek \\
Total cereals & Total of all aforementioned cereal products \\
Full-fat milk & Whole milk from identifiable sources and whole milk from recipes \\
Reduced-fat milk & Low-fat and skimmed milk from identifiable sources and from recipes \\
Cheese & Full-fat and reduced-fat cheese from identifiable sources and cheese from recipes \\
Yoghurt & Full-fat and reduced-fat yoghurt from identifiable sources and yoghurt from recipes \\
Cream & Cream from identifiable sources and cream from recipes \\
Ice cream & Ice cream from identifiable sources and ice cream from recipes \\
Total dairy & Total of all aforementioned dairy products
\end{tabular}

${ }^{*}$ Cereal and dairy products from identifiable sources are those that the respondent recorded eating (e.g. rice), and cereal and dairy products from recipes are the portions found in recipes (e.g. the cheese in an omelette).

†The food groups ready-to-eat breakfast cereals and other breakfast cereals were aggregated for nutrient analysis. 